\title{
UM ESTUDO SOBRE A LEGISLAÇÃO PARA O ENSINO DE MÚSICA NAS SÉRIES INICIAIS DO ENSINO FUNDAMENTAL NAS TRÊS CAPITAIS DA REGIÃO SUL DO BRASIL
}

\author{
Sérgio Luiz Ferreira de Figueiredo ${ }^{1}$; Dyane da Silva Rosa ${ }^{2}$ \\ Departamento de Música - CEART - UDESC \\ Projeto de Pesquisa: Os efeitos da legislação educacional para a educação musical nas séries \\ iniciais: 10 anos de LDBEN e outros documentos. \\ Grupo de Pesquisa MUSE - Música e Educação \\ sergiofigueiredo@udesc.br; dyanerosa@gmail.com
}

\begin{abstract}
RESUMO
Neste artigo encontra-se a análise de alguns resultados da pesquisa intitulada: Os efeitos da legislação educacional para a educação musical nas séries iniciais: 10 anos de LDBEN e outros documentos. $\mathrm{O}$ objetivo da pesquisa é investigar de que forma a legislação educacional tem sido produzida em diversos sistemas educacionais a partir das normatizações da LDBEN de 1996. Este artigo apresenta um recorte da investigação referente ao estudo da legislação para a música nas séries iniciais do ensino fundamental em municípios brasileiros. A metodologia qualitativa norteia este trabalho, com ênfase na análise documental. Foram analisados documentos das três capitais dos estados da região sul do Brasil (Curitiba - PR, Florianópolis - SC, Porto Alegre - RS). Os resultados indicam a presença de orientações para a área de música no currículo escolar das séries iniciais do ensino fundamental. Ao mesmo tempo evidencia-se a possibilidade e necessidade de revisão e aprimoramento de tais orientações nos documentos nas capitais investigadas.
\end{abstract}

PALAVRAS-CHAVE: educação musical, anos iniciais do Ensino Fundamental, legislação educacional.

\section{Introdução}

Este trabalho é resultado da análise de dados parciais coletados através da pesquisa intitulada: Os efeitos da legislação educacional para a educação musical nas séries iniciais: 10 anos de LDBEN e outros documentos. O objetivo desta pesquisa é investigar as conseqüências das determinações das leis nacionais vigentes com relação ao ensino de música nos primeiros anos do ensino fundamental.

Através da análise de toda a documentação encontrada, tanto quanto a literatura usada para fundamentar discussões, é possível se fazer uma análise crítica como tambémfazer

\footnotetext{
${ }^{1}$ Orientador. Departamento de Música.

${ }^{2}$ Bolsista PIBIC.
} 
propostas para a melhoria da legislação educacional brasileira, buscando soluções quanto à presença da educação musical nas séries iniciais. E é esse um dos objetivos da pesquisa.

O presente artigo contém uma breve revisão de literatura, a descrição da metodologia adotada e uma breve análise dos dados coletados. Foi selecionada a região sul do Brasil, sendo que serão analisados os documentos de três capitais: Curitiba - PR, Florianópolis - SC e Porto Alegre - RS. Com a análise e discussões apresentadas pretende-se conhecer mais sobre o ensino de música nas séries iniciais através dos documentos orientadores produzidos nas referidas capitais.

\section{LDBEN}

A Lei de Diretrizes Bases da Educação Nacional - LDBEN (BRASIL, 1996) institui princípios básicos para a formação educacional do cidadão brasileiro. No texto da lei está expresso que Estados e Municípios deverão construir sua proposta curricular respeitando uma parte comum nacional, incluída uma parte diversificada de acordo com as especificidades de cada região (BRASIL, 1996, art. 10 e 11).

No capítulo dois da LDBEN, o ensino de arte passa a compor obrigatoriamente o currículo escolar da educação básica: “o ensino da arte constituirá componente curricular obrigatório, nos diversos níveis da educação básica, de forma a promover o desenvolvimento cultural dos alunos" (BRASIL, 1996, art. 26, par. $2^{\circ}$ ). A partir desta normatização fica instituído que todo cidadão deve ter direito ao acesso à arte.

A legislação anterior a 1996 dispunha sobre a "Educação Artística" na escola. A partir da LDBEN de 1996 este termo foi extinto, sendo substituído por ARTE. Esta não é apenas uma questão de nomenclatura, já que diversos autores têm discutido a questão da educação artística, da polivalência, da presença de um único professor responsável por todas as áreas artísticas, mostrando que tais experiências superficializaram a presença das artes nos currículos escolares.

As críticas à polivalência e ao esvaziamento da prática pedagógica em Educação Artística vão se fortalecendo... Difunde-se, conseqüentemente, a necessidade de se recuperar os conhecimentos específicos de cada linguagem artística, o que se reflete, inclusive, no repúdio à denominação "educação artística", em prol de "ensino de arte" - ou melhor, ensino de música, de artes plásticas, etc. Isto se reflete na nova LDB - Lei 9.394, homologada em 1996, após um longo processo de elaboração -, que também dispensa aquela expressão. (Penna, 2004, p. 22) 
Existe Resolução do Conselho Nacional de Educação (BRASIL, 2006), que extingue definitivamente o termo "Educação Artística", reforçando a proposta da própria LDBEN quando não emprega mais esta denominação para tratar do ensino das artes. Apesar das críticas ao modelo educacional da educação artística, e mesmo existindo legislação específica sobre esta matéria, a prática polivalente para as artes é ainda encontrada em diversos sistemas educacionais.

\title{
PCN
}

Os PCN - Parâmetros Curriculares Nacionais (BRASIL, 1997a) - são documentos sem caráter obrigatório que servem de referência na orientação da prática pedagógica e na formulação do currículo escolar. Neste documento são explicados como cada área de conhecimento deve ser desenvolvida na escola.

Um dos volumes dos PCN é dedicado à Arte, dividindo esta área em quatro modalidades: artes visuais, teatro, dança e música. "É, portanto, significativa a presença da música, com proposta própria, nos PCN-Arte, e muitos educadores da área musical encaram este fato como um retorno dessa linguagem artística às escolas” (PENNA, 2001, p. 114).

Para cada modalidade artística os conteúdos são expostos de acordo com três eixos: produção, fruição e reflexão. A música desta forma ganha três grupos temáticos para desenvolver seus conteúdos: “1) Comunicação e Expressão em Música: Interpretação, Improvisação e Composição; 2) Apreciação Significativa em Música: Escuta, Envolvimento e Compreensão da Linguagem Musical; 3) A Música como Produto Cultural e Histórico: Música e Sons do Mundo" (BRASIL, 1997b, p.54-56).

Fonterrada (2004) discute o texto dos PCN destacando que existe uma

\begin{abstract}
ênfase muito grande no verbal, em detrimento da prática artística. Por mais importante que seja falar de música, essa prática não pode substituir a musical. O modelo de ensino trazido aos documentos pela equipe de governo não dá conta da diversidade nacional e regional, tampouco da organização efetiva da prática musical na escola. (Fonterrada, 2004, p. 38 - 39)
\end{abstract}

Sendo a música uma parte constituinte da Arte, nem sempre ela é entendida como uma área que possui conteúdos específicos e desta forma não é assumida como uma disciplina propriamente dita. Esta idéia está de certa forma amparada pelo texto dos PCN, já que não há clareza suficiente para se compreender de que forma as artes deveriam estar presentes no 
currículo. Soma-se a isto a flexibilidade concedida pela legislação na escolha das áreas artísticas que serão contempladas nos currículos.

\footnotetext{
O que parece mais grave é que a própria legislação permite que cada sistema educacional decida sobre sua organização, o que pode significar a presença ou ausência de várias linguagens artísticas, de acordo com a vocação, o interesse e a compreensão que se tem sobre o ensino das artes na escola. (FIGUEIREDO, 2005, p. 24)
}

Percebe-se que os PCN deixam brechas para diferentes interpretações que tanto podem dificultar a formulação de diretrizes curriculares nos estados e municípios. As diversas interpretações não estimulam a presença de música nos currículos escolares, já que cada sistema educacional pode dispor do ensino de arte da forma que considerar mais conveniente.

Há ainda outra questão que pode dificultar a inclusão da música na escola. O professor que leciona nas quatro primeiras séries do ensino fundamental, dificilmente está apto a lecionar música por uma deficiência em sua formação no curso de ensino médio e formação superior, como relata Penna (2001). A legislação vigente também não apresenta clareza quanto à formação do profissional que deveria ensinar as diferentes modalidades artísticas nas séries iniciais.

\section{Metodologia}

As reflexões que estão sendo evidenciadas neste artigo, são resultados de uma pesquisa orientada pela metodologia qualitativa, focada na análise documental. Os dados foram coletados em duas etapas: 1) foram consultados websites das Secretarias de Educação de todas as capitais dos estados brasileiros em busca de documentos e orientações para o ensino de música nas séries iniciais do ensino fundamental; 2) foram enviadas cartas para as Secretarias de Educação das mesmas capitais solicitando informações e documentos adicionais que tratassem do ensino de música nas séries iniciais nas instituições educacionais.

Este texto apresenta um recorte da pesquisa realizada, focalizando a análise e a discussão na região sul do Brasil. Os documentos consultados para esta análise encontram-se na Tabela 1 . 


\begin{tabular}{|l|c|c|c|}
\hline \multicolumn{1}{|c|}{ Região Sul } & Curitiba & Florianópolis & Porto Alegre \\
\hline $\begin{array}{l}\text { Documentos encontrados em website da } \\
\text { Secretaria de Educação }\end{array}$ & $\mathrm{X}$ & & $\mathrm{X}$ \\
\hline Resposta à correspondência enviada $^{2}$ & $\mathrm{X}$ & & \\
\hline Documentos complementares $^{3}$ & & $\mathrm{X}$ & \\
\hline
\end{tabular}

Tabela 1 - Região sul do Brasil - documentos coletados e analisados

\title{
Porto Alegre
}

Em consulta feita à proposta curricular encontrada no site da Prefeitura Municipal de Porto Alegre (PORTO ALEGRE, 2008a), pode-se constatar que o ensino fundamental é dividido em ciclos. No primeiro ciclo o ensino da arte é apresentado como uma disciplina ministrada por um professor especialista. No segundo ciclo o documento indica a presença de um professor de arte-educação. E no terceiro ciclo aparece uma especificação para o professor de arte-educação, que pode ser um profissional das artes plásticas, cênicas ou música.

Entendendo que a Educação de Jovens e Adultos - EJA - também abrange o ensino fundamental, incluindo as séries iniciais, documento específico para esta modalidade foi consultado. O termo 'educação artística' ainda é utilizado, mesmo depois da existência de uma legislação que suprime esta denominação.

\begin{abstract}
Dessa forma, busca-se romper com a "divisão de tarefas", típica dos objetivos curriculares tradicionais, expressos em fórmulas - tão absurdas do ponto de vista cognitivo quanto não funcionais pedagogicamente do tipo: aprende-se a pensar logicamente em Matemática, escrever corretamente em Língua Portuguesa, a avaliar criticamente a realidade em Estudos Sociais, a desenvolver o potencial criativo em Educação Artística, a conhecer o próprio corpo e o mundo físico em Ciências, etc. Tais objetivos ou são perseguidos conjuntamente por cada disciplina em particular e por todas em seu conjunto, ou dificilmente sairão do papel para sala de aula. (Porto Alegre, 2008b)
\end{abstract}

Analisando um edital de concurso público de 2003 (PORTO ALEGRE, 2008c), pode-se notar a existência de professores de educação musical na rede pública de ensino.

\footnotetext{
${ }^{3}$ Este documento complementar da cidade de Florianópolis refere-se às atuais orientações para as diversas áreas do currículo, publicadas em 2008. O uso deste documento deve-se ao fato de não haver informação no website da Secretaria de Educação sobre os tópicos para esta pesquisa, nem houve resposta à correspondência enviada pelo pesquisador. Desta forma, foi consultado este documento de 2008 para as discussões sobre a música na rede municipal de Florianópolis.
} 
Mesmo não mostrando o número de vagas, encontra-se no documento, inscrição para área de docência em Educação Musical, sendo exigida a habilitação em Licenciatura Plena de Educação Artística/Música para lecionar no nível do ensino fundamental e médio.

No estudo dos documentos encontrados, podem-se constatar alguns aspectos que precisam de maiores esclarecimentos. Quanto ao que foi consultado no site, podem-se encontrar alguns termos desatualizados. O termo "Educação Artística" foi definido pela Lei 5.692/71. Mas de acordo com a LDBEN de 1996 o termo "Educação Artística" foi substituído pelo "ensino de arte". Este município mantém inadequadamente o uso da educação artística, já que existe normatização mais recente que extingue tal termo da educação brasileira. $\mathrm{O}$ site pode estar desatualizado ou existe a necessidade de revisão da denominação para a área de arte naquele município.

Outro ponto importante que mereceria ser revisto é que os documentos não deixam clara a obrigatoriedade ou não da presença da música no ensino básico. Mas ao mesmo tempo encontra-se um edital de concurso público para professor que mostra a existência de espaço para um educador musical na escola. Mesmo compreendendo positivamente este edital que garante a presença de professores de música naquela rede escolar, não há clareza nem indicação da música nas séries iniciais.

\section{Florianópolis}

A Proposta Curricular da Rede Municipal de Ensino de Florianópolis publicada em 2008 foi o documento analisado referente a este município. No documento é narrada a trajetória do ensino de artes no município que vem elaborando normatizações para o currículo escolar levando em consideração as orientações nacionais. No documento é enfatizada a discussão sobre o ensino de artes de forma polivalente e como este se torna inadequado ao decorrer dos anos. A Secretaria de Educação de Florianópolis há dez anos trabalha com a perspectiva de professores específicos em cada linguagem nas escolas a partir da $5^{\mathrm{a}}$ série. Apresenta, a partir dessa discussão, soluções práticas, como contratação de novos professores para o ensino das artes nas escolas do município de forma a atender a todas as artes e suas especificidades. "Cada linguagem artística guarda, em relação às demais artes, aspectos que lhe são peculiares e é dentro deste entendimento que se organiza e se busca fundamentar a presença das Artes no currículo" (FLORIANÓPOLIS, 2008, p. 89). 
Desta forma, o ensino de artes no município de Florianópolis se mostra preocupado com a aprendizagem de cada linguagem artística e seu ensino individualizado para os alunos das escolas municipais. Para isso no documento é colocado de forma clara e objetiva como o ensino de artes é trabalhado em suas escolas. As linguagens artísticas presentes são: música, teatro, artes visuais e dança. Para música, artes visuais e teatro o município conta com professores efetivos da área para o ensino de cada linguagem. Para a dança, a Prefeitura de Florianópolis oferece algumas experiências para os alunos através de projetos especiais, não tendo ainda em seu quadro professores específicos desta área. Existem poucos profissionais habilitados nesta área no Brasil, mas a prefeitura se mostra interessada em obter soluções para a área dança no futuro.

A proposta curricular do município de Florianópolis apresenta vários relatos de projetos e experiências ocorridas em escolas municipais nas diferentes áreas, incluindo relatos sobre música. Os relatos foram escritos pelos próprios professores atuantes nas escolas. Através destes relatos verifica-se que a música está inserida de forma específica no currículo escolar em alguns anos a partir da $5^{\text {a }}$ série do ensino fundamental. Os relatos são de experiências bem sucedidas, ganhando destaque a questão da interdisciplinaridade, incluindo as séries iniciais.

\footnotetext{
A escola, com este projeto, oportunizou um olhar para outro saber e mostrou que é possível implantá-lo em todas as escolas de $1^{\circ}$ ano a $4^{\circ}$ série do município. Entende-se que a música na escola, principalmente fazendo parte do currículo escolar, abre um novo horizonte com perspectiva de obter resultados significativos quanto à aprendizagem e desenvolvimento global da criança e do adolescente, e que assim se transforma em mais uma ferramenta na construção do sucesso escolar. Também se acredita que, se está buscando uma educação voltada para a desigualdade social, então é direito de todos terem acesso à cultura. (FLORIANÓPOLIS, 2008, p. 109).
}

Apesar desta referência a experiências que envolvem as séries iniciais com a música, no documento analisado não são encontradas referências sobre a existência efetiva do ensino da música nas séries iniciais. O documento não traz informações acerca do profissional que deveria ensinar música nas séries iniciais, repetindo, de certa forma, o modelo dos documentos nacionais que também são imprecisos com relação a esta informação.

É indispensável que a própria comunidade escolar compreenda a importância da presença da educação musical na escola, como disciplina curricular. Hummes (2004) resgata Paulo Freire, enfatizando a idéia de que "a música na sociedade e no contexto escolar pode ser transformadora, portanto ela deve assumir um papel mais definido no ensino escolar ( $p$. 
20). Desta forma, as séries iniciais do ensino fundamental em Florianópolis poderiam ter a música claramente definida como um dos conteúdos a serem incluídos na escola.

\section{Curitiba}

Analisando documentos do município de Curitiba coletados no período de outubro de 2007 a abril de 2008 foi possível identificar tópicos para a discussão a respeito do ensino de Música nesta capital. Os documentos analisados foram: Diretrizes Curriculares vol. 3 (CURITIBA, 2006), Instrução Normativa 02/02 EE - SME (CURITIBA, 2002), coletados na internet e Ofício SME enviado por e-mail (CURITIBA, 2007).

A Instrução normativa/02, de 02 de outubro de 2002 “institui carga horária de $110 \mathrm{~min}$ obrigatórios para o Ensino de Arte e professor específico para esta atuação, independente de sua formação" (CURITIBA, 2002). O ensino de Arte nas séries iniciais possui carga horária mínima e, mesmo sendo em número reduzido, há professores com habilitação específica trabalhando na rede municipal.

Pela resposta à correspondência enviada pela Secretaria de Educação de Curitiba, foi possível constatar que a educação musical se faz presente na educação básica das escolas do município. Em relação a professores de música a correspondência informa a situação atual (em novembro de 2007).

No momento temos informação de 9 professores habilitados (em música) atuando num universo de 171 escolas. Os demais que atuam com música não possuem graduação, mas estão em permanente capacitação. No ano de 2007, 145 professores freqüentaram os cursos de música. (CURITIBA, 2007)

A mesma correspondência enviada pela Secretaria de Educação de Curitiba enfatiza a questão da falta de formação nas diversas áreas artísticas dos professores das séries iniciais e informa que tem oferecido diversas oportunidades de formação nas várias linguagens artísticas através de cursos de capacitação.

Tendo em vista a que a maioria dos profissionais atuantes no Ensino de Arte não possui habilidade específica nas áreas artísticas, a SME promove um intenso programa de formação continuada para estes professores. Os cursos promovidos trabalham com a especificidade de cada área. (CURITIBA, 2007) 
Vale salientar, também, a informação de que o trabalho "desenvolvido da área de música é coordenado e acompanhado por especialista em música da Equipe de Ensino da Arte da SME" (CURITIBA, 2007).

Analisando as Diretrizes Curriculares (vol. 3), a disciplina que compõe o "ensino de arte" é denominada 'Educação Artística' de acordo com a Instrução n. ${ }^{\circ}$ 14/2004 do DIE/CDE/SEED (CURITIBA, 2006, p. 88). O documento afirma que

\begin{abstract}
o ensino da arte contempla o estudo das Artes Visuais, da Música, do Teatro e da Dança, cada qual com o seu objeto de estudo e elementos formais. Desse modo, o professor deverá levar em conta a especificidade de cada linguagem artística, seus objetos de estudo e elementos formais, considerando a totalidade das formas de expressão artística como produção cultural, social e histórica. (CURITIBA, 2006, p. 90-91)
\end{abstract}

A importância de ensinar diversas linguagens artísticas é reforçada no mesmo documento. De acordo com as diretrizes do município de Curitiba

cabe ao ensino da arte a tarefa de proporcionar ao estudante o conhecimento dos códigos das diferentes linguagens artísticas, no sentido de instrumentalizá-lo para a leitura e a interpretação, e o desenvolvimento da capacidade criadora ou criatividade estética para a auto-expressão. (CURITIBA, 2006, p. 89)

Em todos os ciclos (de primeira a nona série) do Ensino Fundamental são apresentados objetivos, conteúdos e critérios de avaliação para o ensino de cada modalidade artística. Analisando os documentos encontrados, pode-se perceber a clareza nas informações, que indicam desde a carga horária das disciplinas, até os conteúdos que devem ser lecionados em cada linguagem artística.

\title{
Considerações Finais
}

Esta breve análise de documentos oficiais para o ensino da música nas séries iniciais das três capitais dos estados da região sul do Brasil mostra que os municípios analisados contemplam o ensino de música no ensino básico. Faltam informações precisas que esclareçam se o ensino de música está efetivamente presente nas séries iniciais em Porto Alegre e Florianópolis. Curitiba é o único município analisado que traz esta informação clara, tendo os documentos a preocupação em detalhar todo o trabalho desenvolvido com música nas escolas do município.

A flexibilidade existente nas determinações dos documentos nacionais para o ensino de arte nas séries iniciais podem ser, de certa forma, verificada nos documentos brevemente 
analisados neste texto. Florianópolis critica a polivalência para as artes, contratando professores específicos em cada linguagem artística, mas tais professores não estão necessariamente atuando nas séries iniciais. Curitiba investe na formação continuada dos professores generalistas que normalmente não possuem formação em artes, garantindo, de alguma forma, a presença da música no currículo. Porto Alegre realiza concursos por área específica, mas os documentos não indicam a obrigatoriedade da música nos anos iniciais da escola. Estes são três exemplos de interpretações diferentes da mesma legislação, o que evidencia que diferentes sistemas educacionais podem ou não incluir a música nas séries iniciais.

Diante deste quadro, a revisão de documentos oficiais que tratam das orientações para a música e para as artes nas séries iniciais é necessária para que tal formação seja oferecida a todos os estudantes. O aprimoramento desta legislação depende da ação conjunta de profissionais da educação, administradores e toda a sociedade que deve participar do processo de melhoria da qualidade da educação brasileira. A educação musical deve fazer parte desta ação educativa de forma efetiva contribuindo para a formação integral de todos aqueles que passam pela escola.

\section{REFERÊNCIAS BIBLIOGRÁFICAS}

BRASIL. Lei de Diretrizes e Bases da Educação Nacional (9394/96). Brasília: Diário Oficial da União, 1996.

BRASIL. Ministério da Educação e do Desporto. Secretaria de Educação Fundamental. Parâmetros Curriculares Nacionais. Brasília: 1997a. Disponível em: http://www.mec.gov.br/sef/estrut2/pcn/pcn1a4.asp. Acesso em: 02 de jun. 2008.

BRASIL. Ministério da Educação e do Desporto. Secretaria de Educação Fundamental. Parâmetros Curriculares Nacionais. Arte. Brasília: 1997b. Disponível em: http://www.mec.gov.br/sef/estrut2/pcn/pcn1a4.asp. Acesso em: 02 de jun. 2008.

BRASIL. Resolução CNE/CEB No 1/2006. Solicitação de retificação do termo que designa a área de conhecimento "Educação Artística” pela designação "Arte, com base na formação específica plena em uma das linguagens: Artes Visuais, Dança, Música e Teatro”. Brasília: CNE/CNB, 2006. 
CURITIBA. Instrução Normativa $n^{o}$ 02/02 - EE/SME. Curitiba: Secretaria Municipal de Educação, 2002.

CURITIBA. Diretrizes Curriculares v. 3. Curitiba: Secretaria Municipal de Educação, 2006.

CURITIBA. Carta enviada ao pesquisador. Curitiba: Secretaria Municipal de Educação, 2007.

FIGUEIREDO, Sérgio Luiz Ferreira de. Educação musical nos anos iniciais da escola: identidade e políticas educacionais. Revista da ABEM, número 12. Porto Alegre, RS: ABEM, 2005.

FLORIANÓPOLIS. Proposta Curricular - Rede Municipal de Ensino. Florianópolis: Prefeitura Municipal, 2008.

FONTERRADA. M. T. de O. Reflexões a respeito do ensino de música em escolas que não são de música. In: II Encontro de Pesquisa em Música da Universidade Estadual de Maringá. Maringá: Massoni, 2004. p. 34-40.

HUMMES, Júlia Maria. Porque é importante o ensino de música? Considerações sobre as funções da música na sociedade e na escola In Revista da ABEM, número 11. Porto Alegre, RS, ABEM, 2004.

PENNA, Maura. A Dupla dimensão da política educacional e a música na escola: I analisando a legislação e termos normativos. Revista da ABEM, número 10. Porto Alegre, RS ABEM, 2004.

PENNA, M. (org.). Música na escola: analisando a proposta dos PCN para o ensino fundamental. In: É este o ensino de arte que queremos? Uma análise das propostas dos Parâmetros Curriculares Nacionais. João Pessoa: Universitária (UFPB), 2001. p. 113-134.

PORTO ALEGRE. Funcionamento dos ciclos. Disponível em: http://www.portoalegre.rs.gov.br, 2008a. Acesso em: 20/3/08.

PORTO ALEGRE. Proposta Pedagógica (EJA). Disponível em: http://www.portoalegre.rs.gov.br, 2008b. Acesso em: 20/3/08. 
PORTO ALEGRE. Edital 45 - CONCURSO PÚBLICO No 418 - PROFESSOR. Disponível em: http:// www.portoalegre.rs.gov.br/concurso, 2008c. Acesso em: 20/3/08. 